helpful advice and valuable criticism. I am also indebted to Professor Mary Barber, Postgraduate Medical School, London ; Dr. Jean Bradley, Fulham Hospital, London; Dr. J. H. Darrell, Postgraduate Medical School, London; Professor A. El Ghoroury, Institute of Hygiene, Alexandria ; Dr. E. J. L. Lowbury, M.R.C. Industrial Injuries and Burns Research Unit, Birmingham ; Dr. Joan McWilliam, Royal Infirmary, Edinburgh; Dr. L. Parker, Booth Hall Hospital, Manchester; Dr. K. B. Rogers, the Children's Hospital, Birmingham ; Dr. J. K. Schönfeld, Rotterdam ; Professor R. A. Shooter, St. Bartholomew's Hospital Medical School, London ; Dr. M. Véron, Institut Pasteur, Paris ; and Dr. Josephine A. C. Weatherall, Charing Cross Hospital, London, for sending strains and showing interest in this work.
REFERENCES

Barber, M. (1961). F. clin. Path., 14, 2

Darrell, J. H., and Wahba, A. H. (1964). Ibid., 17, 236.

Finland, M., Jones, W. F., and Barnes, M. W. (1959). F. Amer. med. Ass., 170, 2188. Forkner, C. E., Frei, E., Edgcomb, J. H., and Utz, J. P. (1958). Amer.

Habs, I. (1957). Z. Hyg. Infekt-Kr., 144, 218.

Kleinmaier, H. (1957). Zbl. Bakt., I. Abt. Orig., 170, 570.

Sandvik, O. (1960). Acta path. microbiol. scand., 48, 56.

Véron, M. (1961). Ann. Inst. Pasteur, 101, 456.

Wahba, A. H. (1963). 7. Hyg. (Lond.), 61, 431.

- (1964). Thesis, University of London.

- and Lidwell, O. M. (1963). F. appl. Bact., 26, 246.

\title{
An Investigation of Tropical Splenomegaly at Mulago Hospital, Kampala, Uganda
}

\author{
P. D. MARSDEN,* M.B., M.R.C.P. ; M. S. R. HUTT, M.D., M.R.C.P. ; N. E. WILKS, † PH.D. ; A. VOLLER,* PH.D. ; \\ V. BLACKMAN, M.B., B.S., D.C.P.; K. K. SHAH, M.B., B.S.; D. H. CONNOR, $\ddagger$ M.D. ; \\ P. J. S. HAMILTON,* M.B., CH.B. ; J. G. BANWELL, M.B., M.R.C.P. ; H. F. LUNN, F.R.C.S.
}

Brit. med. F., 1965, 1, 89-92

Idiopathic, cryptogenic, or tropical splenomegaly, as it is variously termed, is often encountered at the Mulago Hospital in Kampala. Trowell (1950) reported several cases in which no good reason could be found for gross splenomegaly, and discussed the current theories of aetiology. Leather (1961) made the important observation that many cases had a mild portal hypertension in the absence of any evidence of cirrhosis on liver biopsy. Of the 41 cases he investigated 29 showed sinusoidal infiltrates by lymphocytes, histiocytes, and plasma cells, an appearance that had been noted elsewhere in the tropics by Fawdry (1955) from Aden, and by Chaudhuri et al. (1956) from India.

The present report describes a series of cases of marked splenomegaly admitted to the New Mulago Hospital, Kampala, in which combined clinical, haematological, parasitological, and pathological investigations were carried out to assess the cause and effect of the large spleens.

\section{Materials and Methods}

Over a period of eight months 64 patients with marked splenomegaly were investigated in the New Mulago Hospital, Kampala.

Routine haematological investigations were prepared by standard techniques (Dacie, 1956). In five patients the red-cell survival and splenic uptake were estimated, using ${ }^{51} \mathrm{Cr}$-tagged red cells (Mollison and Veall, 1955), and the sites of red-cell destruction were assessed by the method of Hughes Jones and Szur (1957).

Standard liver-function tests were done in all cases and a bromsulphthalein excretion test in seven. A needle liver biopsy was performed in 58 of the 64 patients. Two patients refused biopsy and in four a definite diagnosis was possible without biopsy. Repeat biopsies were done in several cases if the first biopsy was unsatisfactory or inconclusive. \footnotetext{
* Seconded from the London School of Hygiene and Tropical Medicine.
+ Walter Reed Army Institute of Research, Washington, D.C., U.S.A. ¥ Armed Forces Institute of Pathology, Washington, D.C., U.S.A.
}

Splenic biopsies were carried out in 17 patients. Twenty-six cases had splenovenograms and in 37 the intrasplenic pressure was estimated by the percutaneous route (Dreyer and BudtzOlsen, 1952 ; Atkinson and Sherlock, 1954). Splenic puncture specimens were examined for malaria parasites and leishmaniae. Initially, random peripheral thick blood was examined for malaria parasites and trypanosomes, but in the latter part of the study a minimum of 10 consecutive daily blood films were examined for malaria parasites by two observers.

Stools were examined by the formol-ether-concentration technique (Ridley and Hawgood, 1956) for ova, cysts, and parasites. Rectal snips were examined for schistosome ova.

Sera from 40 patients were examined by a fluorescent antibody technique (Voller, 1964) for the presence of malarial antibodies. Control sera from patients without splenomegaly were also examined. The antigen used was Plasmodium bastianellii.

Dr. D. J. H. Payne, of the Public Health Laboratory Service in England, kindly examined 40 sera for brucella agglutinins.

\section{Results}

A final analysis of the 64 patients is shown in Table I. The diagnoses are based on both the clinical and the pathological

Table I.-Clinical Conditions and Liver Biopsy Appearances in 64 Patients with Splenomegaly

\begin{tabular}{|c|c|c|c|c|c|}
\hline \multicolumn{4}{|c|}{ Diagnosis } & $\begin{array}{l}\text { Total No. } \\
\text { of Cases }\end{array}$ & Sinusoidal Change \\
\hline $\begin{array}{l}\text { Cirrhosis } \\
\text { Leukaemia } \\
\text { Plasmacytoma } \\
\text { Sickle-cell anaen } \\
\text { Myelosclerosis } \\
\text { Leishmaniasis } \\
\text { Schistosomiasis } \\
\text { Splenic abscess } \\
\text { Brucellosis } \\
\text { Extrahepatic ob } \\
\text { No diagnosis } \\
\text { splenomegaly }\end{array}$ & 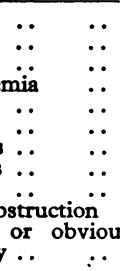 & $\begin{array}{l}\because \\
\because \\
\because \\
\because \\
\because \\
\because \\
\because \\
\text { cause } \\
.\end{array}$ & $\begin{array}{c}\ldots \\
\because \\
\because \\
\cdots \\
\cdots \\
\cdots \\
\text { for } \\
.\end{array}$ & $\begin{array}{r}9 \\
4 \\
1 \\
3 \\
2 \\
2 \\
2 \\
2 \\
2 \\
2 \\
35\end{array}$ & $\begin{array}{l}3 \\
2 \\
0 \\
2 \\
0 \\
0 \\
0 \\
1 \\
2 \\
1 \\
29\end{array}$ \\
\hline Total & $\ldots$ & $\cdots$ & . & 64 & 40 \\
\hline
\end{tabular}


findings. The term "sinusoidal change" refers to infiltration of hepatic sinusoids by lymphocytes as described by Fawdry (1955). Table I shows that over half the cases had no specific cause for their enlarged spleen. Further, there must be some uncertainty about whether the clinical conditions listed were always solely responsible for the splenomegaly.

\section{Liver Biopsy Histology}

All biopsies were acquired with a Vim-Silverman needle and fixed in $10 \%$ neutral formalin. Paraffin sections were prepared in each case and stained routinely with haematoxylin and eosin, and for iron with reticulin.

This description is derived from a study of those 29 cases which showed sinusoidal changes in the absence of other obvious liver disease. The characteristic feature was the presence of large numbers of mature lymphocytes lying in the sinusoids, which were often dilated (Figs. 1 and 2). In some biopsy specimens occasional cells were immature, and very occasionally a cell was seen in mitosis; plasma cells and histiocytes were also seen, though they were rarely present in large numbers. The Kupffer cells were hypertrophied and hyperplastic in nearly all cases, although there did not appear to be an absolute correlation between the lymphocytic infiltration and the Kupffer-cell change. Malarial pigment either in Kupffer cells or in portal

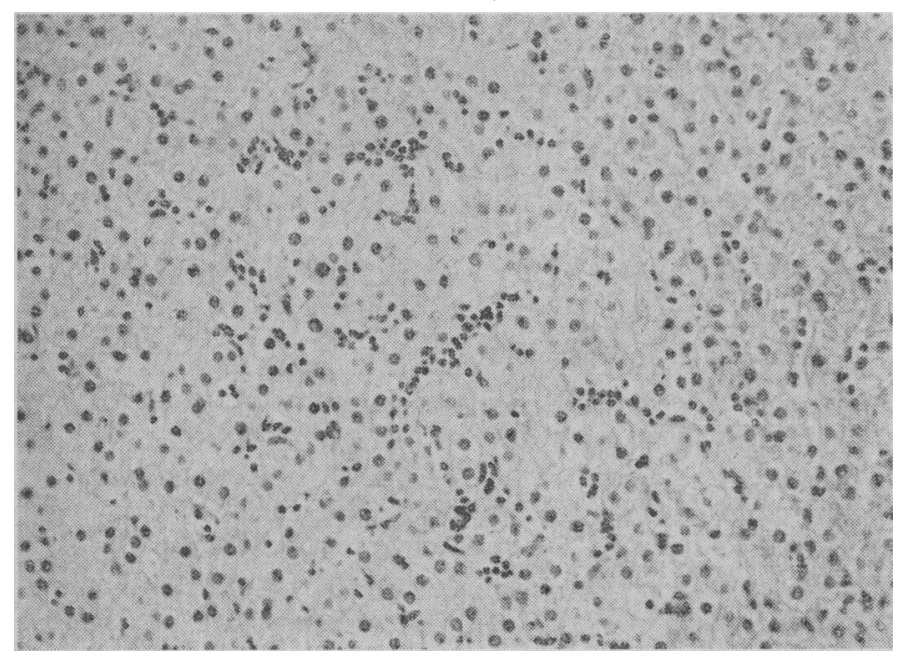

FIG. 1.-Liver biopsy specimen. Low-power view showing lymphocytic infiltration of sinusoids. (H. and E. $\times 175$.)

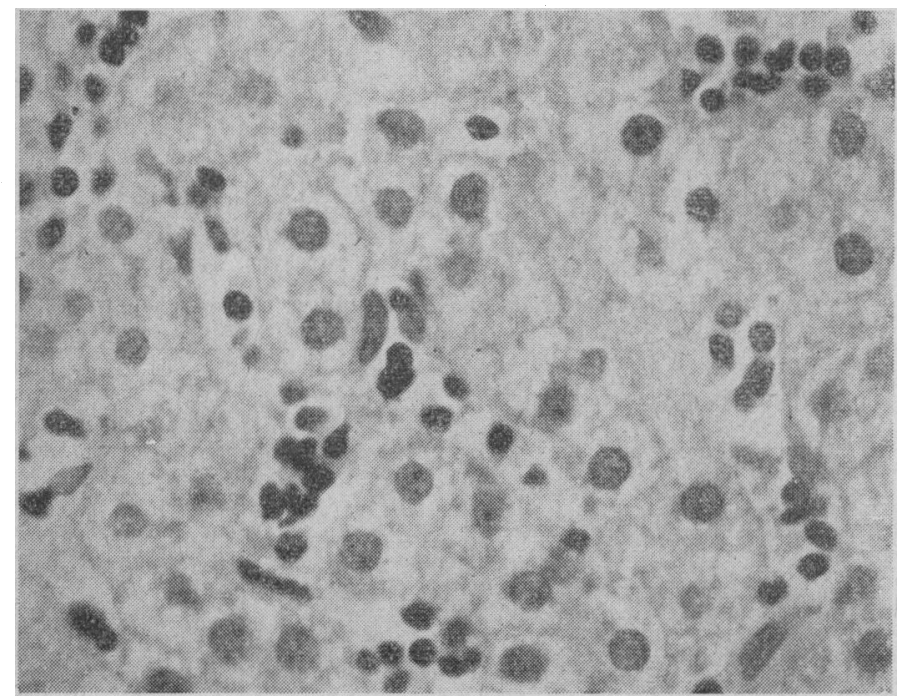

FIG. 2.-Liver biopsy specimen. High-power view showing lymphocytic infiltration of sinusoids with some Kupffer-cell hyperplasia. (H. and E. histiocytes was seen in three cases and in these was inconspicuous. The degree of sinusoidal involvement by lymphocytes was estimated and the findings were graded as follows: marked diffuse involvement (grade 2 ), patchy moderate involvement (grade 1), and patchy minimal involvement (minimal). In subsequent results we refer to these grades, although examination of liver specimens from post-mortem cases suggests that there may be too much variation from one field to another for grading to be accurate on a liver biopsy specimen.

In addition to the mononuclear cells very occasional eosinophils and mast cells were seen in the sinusoids of about $50 \%$ of these biopsies. Trichrome and reticulin stains failed to reveal any constant thickening of the sinusoidal reticulin. Infiltration of the portal tracts by lymphocytes, plasma cells, and eosinophils with some portal fibrosis was often seen but was also seen in biopsies which showed no sinusoidal changes.

In the majority of biopsies with sinusoidal infiltrates liver cells were normal. Neither cholestasis nor liver-cell necrosis was seen. A fuller account of the pathological findings will be published elsewhere.

\section{Clinical, Haematological, and Biochemical Investigations}

Fifteen of the 29 cases with sinusoidal changes but without associated specific diseases were investigated in more detail. There were seven males and eight females, with an average age of 34 years and a range of 17-60 years. Five of the females were pregnant or lactating.

All but one of the 15 patients gave a history of repeated fevers and five had a low-grade fever in the ward. In only one case did the spleen not reach the umbilicus. The patients were usually aware of the enlarged organ and many complained of abdominal pain or discomfort related to the spleen. The duration of the splenomegaly was variable, but all patients measured it in terms of years, and seven said it had been present for longer than five years, sometimes since childhood. The hepatomegaly present in 11 patients was moderate in degree and the liver soft in consistency $(5-10 \mathrm{~cm}$. below the right ninth costal cartilage).

Signs of portal hypertension were present in two patients who had ascites with intrasplenic pressures over $35 \mathrm{~cm}$. of water. Ten of the remaining 13 patients had intrasplenic pressures above $17 \mathrm{~cm}$. of water, which Leather (1961) found to be the mean figure in Kampala controls. Further investigation of the portal hypertension in some of these patients is described in detail elsewhere (Marsden et al., 1964).

Some degree of anaemia was present in all cases, only two having a haemoglobin above $12 \mathrm{~g} . / 100 \mathrm{ml}$. Evidence of haemolysis as judged by increased urinary or faecal urobilinogen, raised serum bilirubin, and increased reticulocyte counts was found in the other 13 cases. No evidence of any haemolytic factor other than hypersplenism was found in these cases. A neutropenia was present in 11 cases and thrombocytopenia in eight. Marrow erythroid hyperplasia was found in the 13 patients with haemoglobin below 12 g. $/ 100 \mathrm{ml}$. and in five with leucopenia there was myeloid maturation arrest. Some megaloblastic change was found in three of the recently pregnant women.

In five patients ${ }^{51} \mathrm{Cr}$-survival times were determined. The average red-cell survival in these cases was 13 days, with a range of 10.5-16 days. Two of these patients showed an excessive splenic uptake with increasing spleen/liver ratio, and one showed excessive uptake in both spleen and liver with steady spleen/liver ratios.

The mean serum albumin in this group was $3 \mathrm{~g} . / 100 \mathrm{ml}$. (normal for Kampala out-patients is $3.15 \mathrm{~g} . / 100 \mathrm{ml}$.) and the serum globulin was $2.74 \mathrm{~g} . / 100 \mathrm{ml}$. (normal for Kampala outpatients is $1.86 \mathrm{~g} . / 100 \mathrm{ml}$.) (A. G. Shaper and P. Leonard, 1964, personal communication). 
There was no evidence of hepatic insufficiency as assessed by bromsulphthalein excretion and thymol turbidity tests, and in a further group of patients serum transaminases have been normal.

\section{Further Investigation in Idiopathic Splenomegaly in Patients with Hepatic Sinusoidal Changes}

Malaria.-Random thick smears were examined initially in all subjects of the series. Plasmodium malariae was revealed in two of them. It was therefore decided to carry out a more detailed search for $P$. malariae. The results of this detailed search for malaria parasites in 20 patients with sinusoidal changes are shown in Table II and compared with the findings in a group of control subjects without splenomegaly. The presence of quartan parasites in 9 out of 20 patients $(45 \%)$ with hepatic sinusoidal changes compared with 1 out of 25 (4\%) controls is significant. It must be emphasized that the parasites were scanty and the infection was always subclinical. In the 11 cases in which no parasites were found attempts to produce parasitaemia with an adrenaline drip, repeated high doses of hydrocortisone, or atropine all failed. Slides were also taken from patients during epileptiform convulsions and in labour, with negative results.

Malarial Antibody Studies.-Sera from 25 patients with hepatic sinusoidal changes, in eight of whom $P$. malariae trophozoites were eventually found, were tested for malarial antibodies using as controls nine cases with a specific cause for splenomegaly but with no sinusoidal changes in the liver biopsy, and eight cases without splenomegaly. The results are shown in Fig. 3. It is evident that there is considerable difference in the distribution of titres in the two groups, those with sinusoidal changes having much higher titres. These figures suggest that

TABLE II.-Results of a Detailed Search for Malaria Parasites in the Two Groups of Patients

\begin{tabular}{|c|c|c|c|}
\hline & & $\begin{array}{l}\text { Patients with } \\
\text { Sinusoidal Changes } \\
\text { on Liver Biopsy } \\
\text { and Splenomegaly }\end{array}$ & Controls \\
\hline $\begin{array}{l}\text { No. of cases . . } \\
\text { No. of slides studied } \\
\text { No. of positive slides } \\
\text { Cases positive } P \text {. malariae } \\
\text { Cases positive } P \text {. falciparum } \\
\text { Cases positive } P \text {. vivax }\end{array}$ & $\begin{array}{ll}\cdots & \cdots \\
\cdots & \cdots \\
\cdots & \cdots \\
\cdots & \cdots\end{array}$ & $\begin{array}{r}20 \\
336 \\
35 \\
9 \\
1 \\
1\end{array}$ & $\begin{array}{r}25 \\
260 \\
1 \\
1 \\
0 \\
0\end{array}$ \\
\hline
\end{tabular}

CONTROL SERA

NO LIVER BIOPSY
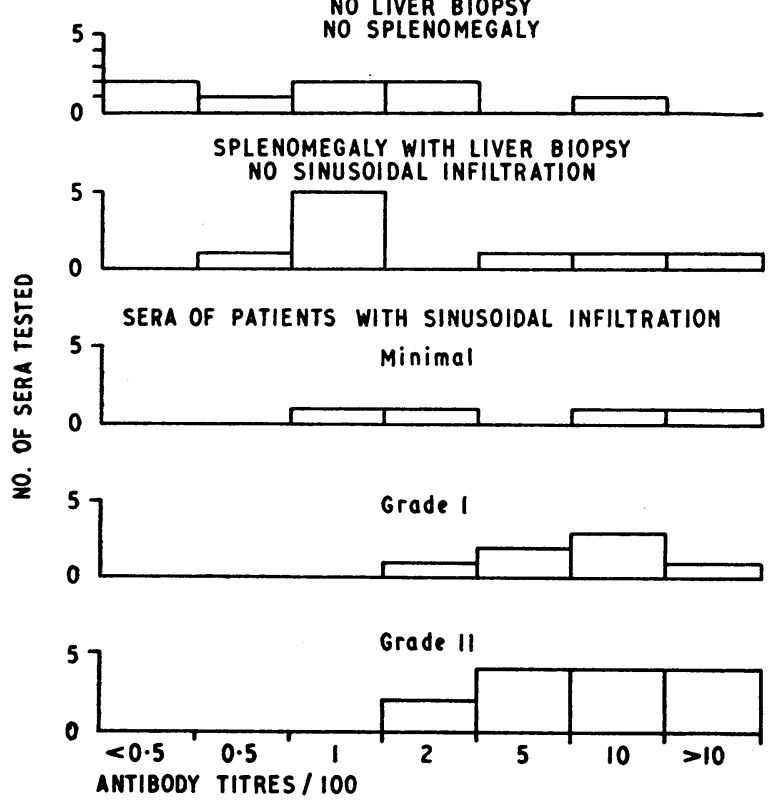

FIG. 3.-Fluorescent antibody titres for malaria. there is some relation between sinusoidal changes and raised malarial antibody titre. These groups are too small for satisfactory statistical analysis, but the results of a further series of cases with additional controls have shown the two groups to be significantly different (Gebbie et al., 1964).

Brucellosis.-Brucella antibodies were estimated in 40 sera, of which only two had a titre which suggested active disease. Both of these subjects had hepatic sinusoidal changes but no evidence of brucella granuloma and from neither patient was the organism cultured.

Other Parasites.-No cases with sinusoidal changes and splenomegaly had evidence of leishmaniasis, trypanosomiasis, or schistosomiasis. Most patients had low-grade hookworm infections.

\section{Discussion}

Any investigation of splenomegaly in the tropics is hampered by the problems of multiple aetiological factors. Further, it seems probable that idiopathic splenomegaly in one tropical country may have an origin different from that in another area. Our investigations indicate that in Uganda a proportion of patients with marked splenomegaly have a chronic malarial infection and that this is associated with reticulo-endothelial hyperplasia of the hepatic sinusoids and also with high fluorescent antimalarial titres.

These changes in the liver have already been referred to briefly by Leather (1961) from Kampala and have been reported in cases of idiopathic splenomegaly occurring in Aden (Fawdry, 1955), in India (Chaudhuri et al., 1956), and in Hong Kong (Cook et al., 1963).

Both Fawdry and Chaudhuri et al. suggested that malaria might be the causal agent, but they had no direct evidence for this. Charmot and Vargues (1963), in an investigation of macroglobulinaemia in Africans, refer to 24 patients with chronic splenomegaly in whom liver biopsy showed dilatation of sinusoids with round-cell infiltration and Kupffer cell hyperplasia. The cause was not detected in any of these cases, but epidemiological studies showed malaria to be the only factor common to the various regions where this splenomacroglobulinaemia occurred. They suggest a possible malarial cause, with some immunological disorder, as reflected by the high globulin level and the presence of macroglobulins.

Descriptions of liver pathology in known cases of malaria usually refer to the changes in acute falciparum infections (Maegraith et al., 1947). Infiltration of sinusoids with chronic inflammatory cells of the lymphocytic, plasma cell, and histiocytic type has been reported in relapsing vivax infections (Corcoran et al., 1953) and in malarial splenomegaly occurring in children from West Africa (Walters and McGregor, 1960). In this latter group, in which there were probably mixed and repeated infections with $P$. falciparum and to a less extent with $P$. malariae, pigment was a constant feature in addition to the chronic inflammatory cells.

The hypothesis of a causal relationship between malaria and idiopathic splenomegaly with hepatic sinusoidal infiltrates is strengthened by the results of the fluorescent antibody studies in this series and in a subsequent group of cases in which more rigid controls were included and which were performed on the double-blind technique (Gebbie et al., 1964). Further, the very high titres support the concept of an unusual immunological response to malaria (Charmot and Vargues, 1963).

$P$. malariae is an organism renowned for its chronicity, due to its persistent exoerythrocytic cycle, and the parasite is often missed on routine examination because of its low density in the peripheral blood. Few serial studies for $P$. malariae have been reported. The finding of this parasite in subclinical infections suggests that the sinusoidal changes and high antibody titre could be secondary to a repeated and prolonged antigenic stimulus by $\boldsymbol{P}$. malariae, which is known to be present throughout much of Uganda. The relative absence of $P$. 
falciparum in the peripheral blood of these patients is noteworthy in view of the frequency with which this parasite is encountered in blood-film surveys in Uganda.

Clinically these patients do not show any specific diagnostic features apart from marked splenomegaly and a lesser degree of hepatomegaly with evidence of secondary hypersplenism and a short red-cell life. Holzbach et al. (1964) have shown that increased red-cell sequestration in the spleen correlates with an increase in splenic size regardless of the underlying cause of the splenomegaly. The association of haemolytic anaemia in pregnancy with splenomegaly, hepatic sinusoidal changes, and a raised malarial antibody titre has also been noted at Mulago (Gebbie et al., 1965, in preparation). Finally, it must be mentioned that the specificity of the malaria antibody test used here is still not precisely delineated. Also the scanty $P$. malariae parasitaemia could be a result rather than the cause of this marked splenomegaly.

\section{Summary}

Patients with large spleens are common in the wards at Mulago Hospital, 64 being investigated in a period of eight months. Like previous workers, we could find no cause for many of the enlarged spleens. An unusual liver-biopsy appearance with sinusoidal infiltrates of lymphocytes and plasma cells was noted in many of the patients in the "idiopathic" group. Most of these patients were anaemic, and Leather's finding of an increased intrasplenic pressure in such cases was confirmed.

In a group of patients with sinusoidal infiltrates $P$. malariae trophozoites were found in the peripheral blood of $45 \%$ of patients after a prolonged search and malarial antibody titres were elevated when compared with control groups. There is therefore a suggestion that $P$. malariae is implicated in a number of such cases in Uganda, and also that the liver biopsy may be helpful in the diagnosis of this syndrome. The relationship between splenomegaly, these hepatic findings, and infection with quartan malaria requires further study.
ADDENDUM.-Since this paper was written eight rhesus monkeys with chronic malarial infections of one to ten years' duration have had liver biopsy specimens examined. These represented simian infections of quartan and vivax types. Only one showed histological changes resembling those described in this paper. This monkey had had the infection for the longest time-namely, 10 years-with Plasmodium inui. Studies on monkeys with long-standing infections are being continued.

We are grateful to the physicians, surgeons, and obstetricians at Mulago Hospital for access to patients and general co-operation; also to Mr. R. Tunnicliffe for the photomicrographs. Financial support was provided by the Leverhulme Trust, the World Health Organization, and by the U.S. Army Medical Research and Development Command, Department of the Army, under Research Grant Number DA-MD-49-193-63-G101.

\section{REFERENCES}

Atkinson, M., and Sherlock, S. (1954). Lancet, 1, 1325.

Acm. Hôp. Paris, 39, 1421.

Chaudhuri, R. N., Saha, T. K., Basu, S. P., Mukheriee, A. M., and Chaudhuri, M. N. R. (1956). Indian f. med. Res., 44, 305.

Cook, J., McFadzean, A. J. S., and Todd, D. (1963). Brit. med. F., 2, 337 .

Corcoran, T. E., Hegstrom, G. J., Zoeckler, S. J., and Keil, P. G. (1953). Gastroenterology, 24, 53.

Dacie, J. V. (1956). Practical Haematology, 2nd ed. Churchill, London.

Dreyer, B., and Budtz-Olsen, O. E. (1952). Lancet, 1, 530.

Dreyer, B., Trans, roy. Soc. trop. Med. Hyg., 49, 387.

Gebbie, D. Hamilton, P. J. S., Hutt, M. S. R., Marsden, P. D., Voller, A., and Wilks, N. E. (1964). Lancet, 2, 392.

Holzbach, R. T., Shipley, R. A., Clark, R. E., and Chudzik, E. B. (1964). f. clin. Invest., 43, 1125 .

Hughes Jones, N. C., and Szur, L. (1957). Brit. F. Haemat., 3, 320.

Leather, H. M. (1961). Brit. med. f., 1, 15

Maegraith, B., Andrews, W. H. H., and Gall, D. (1947). Lancet, 2, 781.

Marsden, P. D., Hutt, M. S. R., and Banwell, J. G. (1964). f. trop. Med. Hyg., 67, 239 .

Mollison, P. L., and Veall, N. (1955). Brit. f. Haemat., 1, 62.

Trowell, H. C. (1950). E. Afr. med. f., 27, 258.

Trowell, H. C. (1950). Bull. Wlth Org., 30, 343.

Walters, J. H., and McGregor, I. A. (1960). Trans. roy. Soc. trop. Med. Hyg., 54, 135.
Withdrawal from a prolonged state of alcohol intoxication is characterized by a variety of symptoms, some of which merely produce discomfort to varying degrees, while others constitute a potential hazard to life (Johnson, 1961). The principal sources of discomfort are sleeplessness, agitation, tremor, sweating, anorexia, nausea, and vomiting. A variable proportion of patients in the withdrawal state, approximately $10 \%$ of those seen in the clinic of this Foundation, develop more dangerous complications, including grand-mal seizures and delirium tremens.

The objectives of treatment for the withdrawal state are principally the amelioration of discomfort arising from the causes mentioned and the prevention of the more serious hazards. In recent years a succession of treatments have been employed, the classical sedatives being replaced to a considerable

* From the Alcoholism and Drug Addiction Research Foundation, Toronto, Canada.

† Professor of Pharmacology, University of Toronto. extent by insulin therapy, and still later by tranquillizers. The replacement of an old treatment by a new one should logically occur only if the new treatment can be shown clearly and objectively to offer advantages over the old. There has been very little objective evaluation of any of the methods employed in the treatment of the alcohol-withdrawal syndrome. The most recent addition to the drug therapy for this condition has been chlordiazepoxide (Librium). To the best of our knowledge there has been no adequately controlled comparison between the efficacy of chlordiazepoxide and that of the various tranquillizers previously in vogue. The present study was therefore devised with two principal purposes: (1) to evaluate the effectiveness of chlordiazepoxide in the treatment of the withdrawal syndrome, in comparison with a typical phenothiazine tranquillizer (promazine: Sparine) and with placebo treatment; and (2) to evolve objectively quantifiable methods which would be applicable to the evaluation of other new drugs that might be proposed for the treatment of alcohol-withdrawal symptoms. 